\title{
Potentiometry, Effect of Solvent and Thermodynamics of Novel Carbohydrazone and Its Transition Metal(II) Complexes
}

\author{
Ahmed A. El-Sherif ${ }^{1, *}$,Elbastweesy R Elbastweesy', Gaber M. Abu El-Reash ${ }^{2}$, Mutlaq S. Aljahdali ${ }^{3}$ \\ ${ }^{1}$ Department of Chemistry, Faculty of Science, Cairo University, Cairo, Egypt. \\ ${ }^{2}$ Department of Chemistry, Faculty of Science, Mansoura University, Mansoura, \\ ${ }^{3}$ Egypt Department of Chemistry, Faculty of Science, King Abd AlAziz University, Jeddah, Kingdom \\ of Saudi Arabia. \\ *E-mail: aelsherif72@yahoo.com
}

doi: $10.20964 / 2019.08 .03$

Received: 3 March 2019 / Accepted: 30 April 2019 / Published: 30 June 2019

The ligand (2E,2'E)-2,2'-(carbonylbis(hydrazine-2-yl-1-ylidene))dipropionic acid (CBHP) had been synthesized and characterized using different tools of analysis. Protonation constants of the novel (2E,2'E)-2,2'-(carbonylbis(hydrazine-2-yl-1-ylidene))dipropionic acid (CBHP) ligand and its corresponding metal-CBHP stability constants with $\mathrm{Cu}(\mathrm{II}), \mathrm{Ni}(\mathrm{II}), \mathrm{Co}(\mathrm{II})$ and $\mathrm{Zn}$ (II) ions were measured in aqueous solution at ionic strength (I) of 0.1 mol.dm ${ }^{-3} \mathrm{NaNO}_{3}$. The order of stability for the formed complexes with reference to the metal ions complies with this order $\mathrm{Cu}$ (II) $>\mathrm{Ni}$ (II) $>\mathrm{Co}$ (II) $>$ $\mathrm{Zn}(\mathrm{II})$ in harmony with the Irving-Williams stability order. The speciation of different species in solution has been assessed as a function of $\mathrm{pH}$. The thermodynamic parameters were calculated and discussed. The effect of solvent on the protonation equilibria of the ligand was also discussed.

Keywords: Carbohydrazone; Complex; speciation; Thermodynamics; Nickel, Potentiometry.

\section{$\underline{\text { FULL TEXT }}$}

(C) 2019 The Authors. Published by ESG (www.electrochemsci.org). This article is an open access article distributed under the terms and conditions of the Creative Commons Attribution license (http://creativecommons.org/licenses/by/4.0/). 